\title{
Diontos
}

Revista de Comunicación Digital

\section{Hashtivismo feminista en Instagram: \#NiñasNoMadres de @actrices.argentinas}

\section{Feminist Hashtivism on Instagram: \#NiñasNoMadres from @actrices.argentinas}

\section{Raquel Tarullo}

raqueltarullo@gmail.com

Centro de Investigaciones y Transferencia del Noroeste de la Provincia de Buenos Aires (UNNOBA-UNSAdA-CONICET)

\author{
Mariana García \\ marugarcia74@gmail.com \\ Universidad Nacional del Noroeste de la \\ Provincia de Buenos Aires (UNNOBA)
}

Recibido: 13/12/2019 Aceptado: 11/03/2020

\section{Resumen}

El uso de las redes sociales como herramientas de movilización ha permitido a diferentes colectivos feministas sumarse, a partir de distintas performances digitales, a las demandas y protestas políticas que transcurren en el espacio urbano. En este sentido, el hashtivismo feminista como recurso de activismo digital en las conversaciones que circulan en los espacios online ha ampliado las posibilidades de convocatoria a distintos públicos. A partir del caso de la campaña \#NiñasNoMadres, protagonizado en Instagram por @actrices.argentinas, un colectivo de actrices argentinas activistas, este artículo aborda el rol del hashtivismo feminista en esta red social que en Argentina es la favorita de los grupos poblacionales más jóvenes. A partir del análisis de contenido de las publicaciones, este estudio permite ubicar flujos de la narración de microhistorias contenidas en el hashtag, pero en diálogo con lo visual y en un contexto de activismo de celebridades.

\section{Palabras clave}

Instagram, hashtivismo feminista, \#NiñasNoMadres, activismo de celebridades

\begin{abstract}
The use of social media as a tool for mobilization has allowed different feminist groups to join the demands and political claims that take place in the urban sphere. In this respect, hashtag feminism as a means of digital activism in online conversations has broadened the possibilities of drawing attention from a variety of audiences. Since the launching of the campaign \#NiñasNoMadres, led by a collective of Argentinean actresses activists on Instagram called @actrices.argentinas, this article has discussed the role of hashtag feminism on this social network, which is the favourite among young people in Argentina. From the content analysis of the publications, this case allows us to identify flows of short stories included in the hashtag but in agreement with the visual content within a celebrities' activism context.
\end{abstract}

\section{Keywords}

Instagram, hashtag feminism, \#NiñasNoMadres, celebrity activism

Cómo citar este artículo:

Tarullo, R. y García, M. (2020). Hashtivismo feminista en Instagram: \#NiñasNoMadres de @actrices. argentinas. Dígitos. Revista de Comunicación Digital, 6: 31-54. DOI: 10.7203/rd.v1i6.172 


\section{Hashtivismo feminista en Instagram:} \#NiñasNoMadres de @actrices.argentinas

\section{Introducción}

El hashtag (del inglés hash, almohadilla o numeral y tag, etiqueta) se forma a partir de una o varias palabras, precedidas por el símbolo numeral (\#). Si bien fue Twitter el que popularizó el uso del hashtag (Bruns y Burgess, 2011), otras redes también han incorporado este recurso que permite buscar contenido específico e identificar conversaciones y tendencias de interés para un público determinado (Bruns y Burgess, 2011).

Desde una perspectiva metacomunicativa, los hashtags son analizados a partir de la función que cumplen (Daer, Hoffman y Goodman, 2014; Giannoulakis y Tsapatsoulis, 2016) y allí es donde reside su significado porque "lo que un hashtag hace es más importante que lo que un hashtag es" (Daer et al.2014:13). Una de las funciones del hashtag es la movilización, que busca unificar y motivar intereses políticos similares (Daer et al., 2014). De esta función se desprende el hashtivismo como “protesta discursiva en redes sociales a partir de una palabra, una frase o una oración hecha hashtag" (Yang, 2016: 13) para llamar la atención sobre cuestiones que están ocurriendo y así convocar a la movilización.

Varias investigaciones sobre demandas feministas dan cuenta del hashtivismo como recurso de movilizacióny protesta en espacios digitales: \#YoSíTeCreo(Larrondo, Moralesi-Gras y Orbegozo-Terradillos, 2019), \#Bringourgirlsback (Ofori-Parku y Moscato, 2018), \#yoviajosola (Piñeiro-Otero y Martínez-Rolán, 2016), \#SupportIslandWomen (Myles, 2019), \#Niunamenos (Chenou y Cepeda-Másmela, 2019), \#Abortolegal (Laudano,2018) y \#RespetoAIDolorDeMadre (Acosta y Nevache, este volumen), por citar algunos entre los muchos casos recientes. En este sentido, el hashtivismo feminista tiene su origen en el hashtivismo como un repertorio de acción en espacios virtuales, para dar voz a otros actores/prosumidores que han traducido sus reclamos feministas en acciones colectivas (Clark, 2016).

El uso de los hashtags colabora en la expresión de un público afectivo (Papacharissi, 2015) para conectar y desconectar narrativas, identificar y alejar públicos y dar forma a los eventos en forma de historia (Giaxoglou, 2018). Los hashtags contienen microhistorias (Page, 2012; Giannoulakis y Tsapatsoulis, 2016; Giaxoglou, 2018) narradas desde una intimidad implicante (Khoja-Moolji, 2015). En el caso del hashtivismo, esta implicancia deviene en espacios políticos de conversación y activismo (Georgakopoulou, 2017).

Los hashtags cuentan microhistorias fragmentadas con final abierto, contienen noticias de último momento, acercan a distintos públicos desde un lugar diferente al de las fuentes tradicionales de información porque son promovidos por actores políticos no institucionalizados (Fina y Georgakopoulou, 2012). Los hashtags habilitan, en parte por las conversaciones digitales que se generan a partir de la compartición e incorporación de la propia voz al hashtag, la conformación de colectivos o movimientos que juegan un 
rol central en la adquisición de reconocimiento (Bruns y Burgess, 2011).

Según Clark (2016), la narración y conexión digital de historias personales a partir de los hashtags, si bien se distingue de las formas primeras de feminismo, mantiene ciertas características que se sustentan en el énfasis que el movimiento le ha dado al discurso, al lenguaje y a la narración de historias (Clark, 2016; Clark-Parsons, 2018). De este modo, estos relatos se convierten en microhistorias que un hashtag puede contener y que ofrecen, además, la posibilidad de compartir, sumar, promover, activar.

La participación de prosumidores (Jenkins, Lashley y Creech, 2017) que crean comunidad en relación con la adhesión a un hashtag en su función de movilización (Daer et al., 2014) y la amplificación en red de causas sociopolíticas (Bonilla y Rosa, 2015), dan cuenta de un hashtivismo feminista que en Argentina tiene, al menos, dos ejemplos recientes: \#niunamenos (que resume la lucha contra la violencia de género) y \#abortolegalya (sintetiza la demanda por la legalización del aborto). Ambos movimientos consiguieron la ampliación de las discusiones, la integración de nuevos actores a las conversaciones digitales y la incorporación de las dos temáticas en las agendas institucionales (Chenou y Cepeda-Másmela, 2019).

Este estudio indaga en el caso del hashtivismo feminista \#NiñasNoMadres, a partir de la campaña vehiculizada en Instagram por activistas célebres miembros del colectivo @ actrices.argentinas durante un período de discusión y debate público en Argentina por la falta de aplicación de protocolos de la Interrupción Legal del Embarazo. ${ }^{1}$

Las preguntas que guían esta investigación son las siguientes:

RQ1. ¿Qué imágenes publica @actrices.argentinas para acompañar el hashtag feminista \#NiñasNoMadres?

RQ2. ¿Qué texto acompaña el \#NiñasNoMadres en las publicaciones que formaron parte de la campaña estudiada?

RQ3. ¿Qué tipo de repercusión dentro y fuera de Instagram tuvo la campaña \#NIñasNoMadres protagonizada por @actrices.argentinas?

\section{Marco teórico: activismo, redes y celebridades en contexto}

\subsection{Activismo digital de celebridades}

Las redes sociales han extendido las posibilidades de activismo, ampliando en el espacio digital los repertorios que transcurren en el mundo offline (Annunziata et al., 2016). De esta manera, los formatos tradicionales de militancia se han visto modificados a partir de la interacción de los mismos con novedosas performances que han encontrado en el mundo online otras formas de narrar historias para hacer oír denuncias. En un escenario de autocomunicación de masas (Castells, 2012), las redes sociales son herramientas propicias para fomentar la participación y el activismo ciudadano (Delfino, Beramendi y Zubieta, 2019), difundir conversaciones sobre temáticas que pueden quedar por fuera de la agenda de los medios (Jenkins et al., 2018) y sumar actores en interacciones digitales de movilización, acción y participación (Meraz y Papacharissi, 2013). Estas acciones se acompañan con prácticas de storytelling que adquieren significado en un

1. Desde 2012, un fallo de la Corte Suprema de Justicia, conocido como caso F.A.L, permite la interrupción del embarazo a la mujer, cualquiera sea su condición, cuyo embarazo es producto de una violación. Sin embargo, hay jurisdicciones que no acatan el fallo de la Corte (Gherardi and Gebruers, 2015). 
contexto determinado (Papacharissi y Fatime Oliveira, 2012; Jenkins, 2017).

Este escenario también aplica al activismo de celebridades, que no es nuevo (Jones y Soltren, 2005; Thrall et al., 2008; Larkin, 2009). No obstante, estudios recientes dan cuenta de las performances de famosos en el espacio digital en pos de la visibilización de temáticas de interés político (Gámez Fuentes, Gómez Nicolau y Maseda García, 2016; Ellcessor, 2018; Kwon, 2019). Este activismo impacta en la opinión pública por contar los famosos con una influencia en los medios de comunicación que el ciudadano no tiene (Cox, 2011). Además, captan la atención de los más jóvenes (Cox, 2011; Kwon, 2019), desde un lugar de participación política no convencional (Jenkins, 2017; Jenkins, Lashley y Creech, 2017). Asimismo, el colectivo de activistas famosos/as \#Metoo ha acaparado las miradas en varias investigaciones (Jaffe, 2018; Tambe, 2018; Tippett, 2018; Fileborn y Loney-howes, 2019).

\subsection{Actrices argentinas: activismo y militancia en colectivo}

En Argentina, el colectivo @actrices.argentinas viene de la mano de un activismo de varias décadas, en el que actrices y actores han dado muestra de un fuerte compromiso social y político en este rol de "espejo y testimonio que ayuda a pensar", como sostiene Cristina Banegas, una de las principales referentes en el ámbito nacional de la actuación (Peralta, 2019).

En un ejemplo reciente (Imagen 1) la actriz y cantante Lali Espósito se presentó en la entrega de los premios Grammy Latino 2018 con el pañuelo verde, símbolo de la

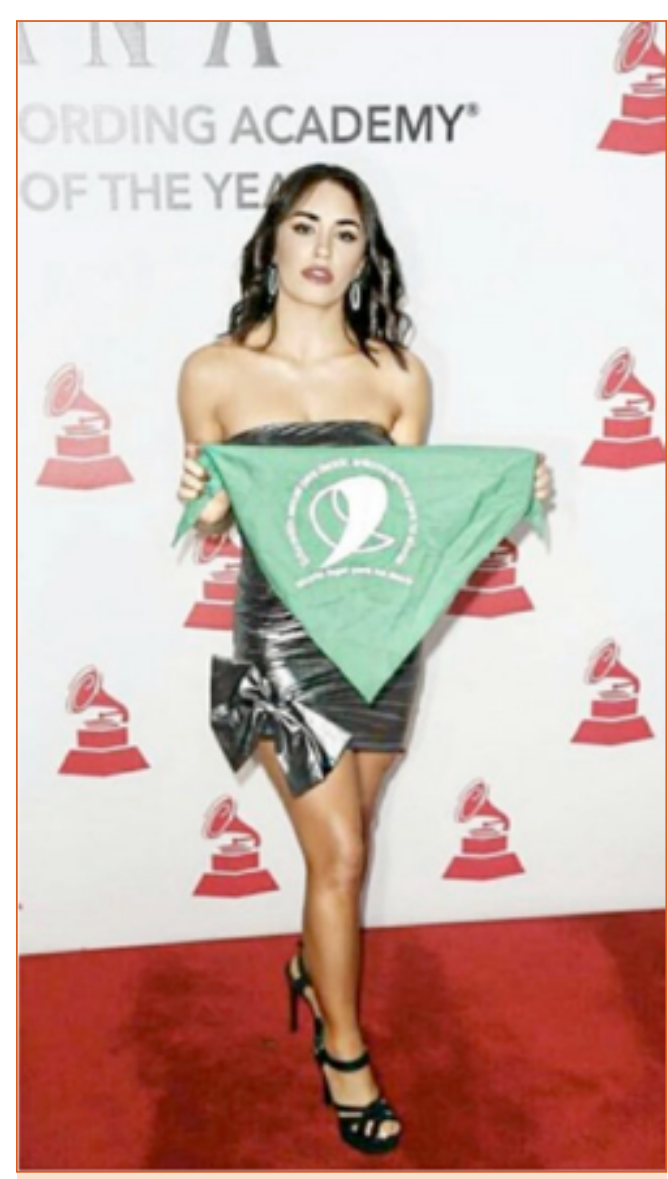

Imagen 1. Lali Espósito en la presentación de los premios Grammy Latino, 18 de noviembre de 2018. | Fuente: eldestapeweb
Campaña Nacional por el Aborto Legal Seguro y Gratuito. Esta acción fue atendida por la prensa y también apareció en su cuenta de Instagram, que con casi siete millones de seguidores, cosecha una profusa interacción entre sus fans digitales (EI destape web, 2018).

El colectivo @actrices.argentinas está formado por 400 actrices. Construyó su rol participativo en tres momentos fundamentales. En primer lugar, con la campaña a favor de la legalización del aborto (Infobae, 2018; Centenera, 2019a). Luego, a partir de las denuncias por abusos sexuales en el medio artístico difundidas en conferencias de prensa (Clarín, 2018; Perfil, 2018). Estas dos cuestiones fueron fundamentales para su visibilización tanto a nivel televisivo como digital (Ámbito, 2018). El tercer momento significativo se ubica con la campaña \#NiñasNoMadres, que se detalla en el siguiente apartado.

\subsection{La campaña \#NiñasNoMadres de las actrices argentinas}

La campaña \#NiñasNoMadres consolida al colectivo en un activismo que excede las demandas del sector para posicionarlo en diálogo con cuestiones de la agenda pública. La campaña que este estudio analiza fue protagonizada por este 
colectivo en Instagram, a partir del uso \#NiñasNoMadres. Comenzó en la cuenta @ actrices.argentinas el 28 de febrero de 2019 con una foto de la actriz Dolores Fonzi de niña, acompañada por un texto (Imagen 2$)^{2}$ que sirve de introducción a toda la campaña.
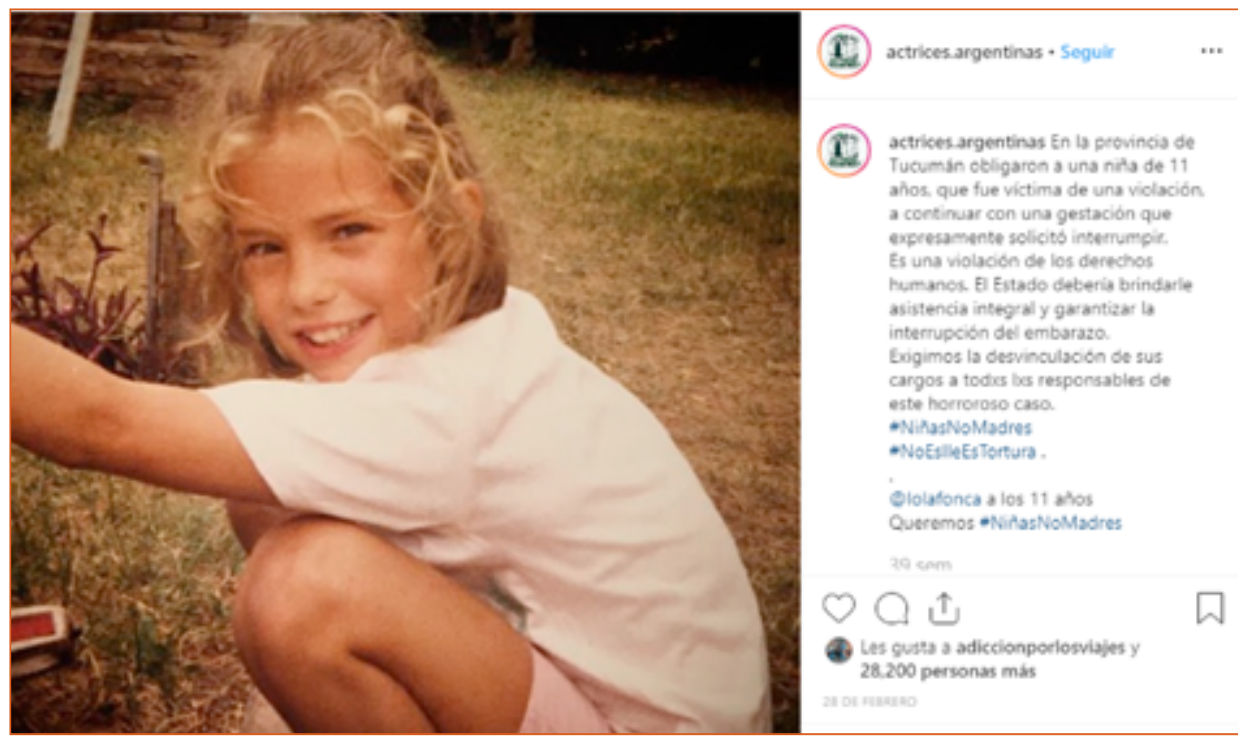

Imagen 2. Posteo que da comienzo a la campana \#Niñasnomadres en la cuenta @actrices.argentinas. 28 de febrero de 2018

Fuente: Instagram

El 23 de enero de 2019, en Tucumán, una niña de 11 años embarazada producto de una violación perpetrada por la pareja de su abuela, solicitó junto con su madre la Interrupción Legal del Embarazo (ILE) permitida para casos de violación o en situaciones de peligro de la salud o vida de la gestante (Safatle, 2019). No obstante, por la demora del proceso a cargo de los funcionarios provinciales, el pedido se dilató y se llevó a cabo la intervención en una situación extrema: todos los médicos y enfermeras dentro del quirófano se declararon objetores de conciencia y la práctica de cesárea fue realizada por doctores del sector privado que fueron convocados para tal función (Safatle, 2019). La beba, de 25 semanas de gestación, nació el 26 de febrero de 2019. Pesó 660 gramos y falleció el 8 de marzo (Infobae, 2019a).

El evento fue noticia en los principales medios de comunicación de Argentina y del extranjero (Centenera, 2019a; The Guardin, 2019). Este caso no es único: en Argentina, los índices de embarazo infanto-adolescente se ubican entre los más altos de la región: cada 3 horas una niña de entre 10 y 14 años tiene un parto y 3,6 nacimientos de cada 1.000 corresponden a una madre de 14 años o menos (UNICEF, 2017).

Asimismo, 1 de febrero de 2019, el diario de tradición conservadora La Nación (Aruguete y Koziner,2014) el segundo en venta en formato papel y la tercera fuente de noticias para los argentinos que se informan en el espacio digital (Newman et al., 2019), publicó una editorial titulada "Niñas madres con mayúsculas" (La Nacion, 2019a). Allí defiende el "instinto maternal" de niñas de 12, 13 y 14 años y su valentía de ser madres a pesar de que, en uno de los casos, ese embarazo haya sido producto de una violación.

2. Se incorporan imágenes que son capturas de pantalla de las publicaciones de @actrices.argentinas, cuyo fin es ejemplificar el análisis que en este artículo se aborda. Los comentarios fueron ocultados. Al ser una página pública de acceso abierto en Instagram, se consideró que no era preciso obtener el consentimiento expreso para sumar las imágenes en este estudio. 
Esta publicación generó un enorme rechazo en distintos medios y organismos internacionales que repudiaron la editorial (Página/12, 2019a), especialmente en las redes sociales, donde se volvió la noticia más viralizada del día en Twitter junto con \#NiñasNoMadres, que además se hizo tendencia (Infocielo, 2019).

El rechazo a la editorial lo expresaron periodistas del propio medio (Agencia de Noticias RedAcción, 2019) y de otros espacios comunicacionales y organizaciones no gubernamentales (Infocielo, 2019).

\subsection{Instagram como espacio digital político}

Si bien la conversación digital sobre la nota editorial publicada por el diario La Nación fue protagonizada en Twitter (Infocielo,2019), nos interesa la repercusión que tuvo en Instagram, una red cuya esencia es la compartición de contenido visual y que además ha sido poco explorada en cuanto a las temáticas de índole público a pesar de su uso creciente para la difusión de cuestiones políticas (Martín García y Martínez Solana, 2019, Tarullo, 2019a). Además, Instagram es una red popular en Argentina: cuenta con 14 millones de usuarios activos, que representan el 31\% de la población, porcentaje que la ubica entre los países latinoamericanos con mayor cantidad de perfiles en esta plataforma (INDEC, 2018; Kemp, 2018). La mayoría de los usuarios tiene entre 18 y 34 años: el 55\% de la comunidad son mujeres y el $45 \%$ son hombres (INDEC, 2018; Kemp, 2018). Asimismo, es la red en la cual los movimientos feministas cuentan con mayor cantidad de seguidores y de prácticas de interacción (Tarullo, 2019b).

Instagram se reconoce por distribuir contenidos y experiencias de la vida cotidiana (Zappavigna, 2016) promoviendo así otros formatos de conectividad y visibilidad (Thompson, 2005; Van Dijck, 2016). Por un lado, ciertos estudios sobre el uso de Instagram concluyen que las performances visuales en esta red se relacionan con formas narcisistas de promoción del self y de fomento de la imagen política (Sampietro y Sánchez-Castillo, 2020) donde influencers e instagrammers se encuentran con sus públicos (Loader y Vromen, 2015; Leaver y Highfield, 2016; Moon et al., 2016) Por otro lado, otros estudios indican que la difusión de producciones visuales en Instagram incide en cuestiones de índole político (Eldin, 2016; Mahoney et al., 2016; Kulkarni, 2017, Tarullo, 2019a), siendo además un espacio propicio para el activismo de celebridades (Cox, 2011; Cornet, 2018). Por ello, investigaciones han observado una tendencia en la incorporación de la plataforma para la amplificación de los repertorios de movilización en temáticas feministas (Martín García y Martínez Solana, 2019, Tarullo, 2019a), que hacen de esta "pantalla íntima" (Khoja-Moolji, 2015), otra forma de activismo digital, en pos de la sensibilización sobre temáticas políticas y que pueden resultar más exitosas que la acción política tradicional (Alexander y Hahner, 2016). La intimidad ha demostrado ser un recurso de activación para alcanzar la sensibilización de los públicos interesados en temáticas de la agenda pública que encuentra en la arquitectura visual de Instagram el espacio para su despliegue y la identificación con la historia -íntimanarrada (Alexander y Hahner, 2016; Giaxoglou, 2018).

\section{Metodología}

Este estudio analiza una performance online de activismo de famosos o de celebridades a partir del uso de hashtag \#NiñasNoMadres, impulsado por el colectivo feminista @ actrices.argentinas en Instagram para ubicar el funcionamiento de este repertorio digital y el rol de la imagen en la narración y difusión de microhistorias de movilización. La metodología para abordar esta investigación es el estudio de caso (Yin, 1989). 


\subsection{Corpus}

El contenido publicado en Instagram por el colectivo feminista @actrices.argentinas los días 28 de febrero y 1 de marzo de 2019, período durante el cual se difundió la campaña, fue recolectado manualmente. Se utilizó el programa FireShot (Softonic, 2019) para capturar las publicaciones individualmente. Las imágenes se recogieron en formato jpg.

Se recolectaron en total 68 publicaciones con imágenes y 6 álbumes de fotos que contenían diferente cantidad de imágenes: dos álbumes de cuatro fotos, dos con cinco, otro con seis y otro conteniendo dos imágenes, que hacen un total de 94 fotografías y ningún video. En todos los casos, las imágenes contenidas en los álbumes fueron consideradas individualmente para su análisis visual. En el caso de los textos incluidos en los álbumes, solo se consideró una vez, ya que cada imagen del álbum repite el texto introductorio. En el caso de las interacciones de los álbumes se consideró la cantidad de likes y comentarios que obtuvo el álbum en total. Para calcular el promedio de interacciones (número de likes y comentarios por posteo) se consideró el álbum como una entrada individual.

Como uno de los álbumes con cinco imágenes fue publicado de forma idéntica en dos oportunidades en la cuenta en estudio, se desechó la segunda entrada. Como el corpus fue recogido el 1 de setiembre de 2019, las interacciones de likes y comentarios pueden haber variado ligeramente con respecto a las fechas de publicación.

Finalmente, el cuerpo de estudio quedó conformado por 89 publicaciones con imágenes y texto. Se diseñó un libro de códigos que por las características del corpus incluyeron variables obtenidas a partir de acercamientos inductivo y deductivo. Para valorar el contenido visual se tomaron los elementos de la definición de infancia del Fondo de las Naciones Unidas para la Infancia (UNICEF, 2005: 3) que reconoce a este período como:

\footnotetext{
"la época en la que los niños y niñas tienen que estar en la escuela y en los lugares de recreo, crecer fuertes y seguros de sí mismos y recibir el amor y el estímulo de sus familias y de una comunidad amplia de adultos. Es una época valiosa en la que los niños y las niñas deben vivir sin miedo, seguros frente a la violencia, protegidos contra los malos tratos y la explotación. Como tal, la infancia significa mucho más que el tiempo que transcurre entre el nacimiento y la edad adulta. Se refiere al estado y la condición de la vida de un niño, a la calidad de esos años".
}

Si bien el activismo en contextos digitales es un tema de interés para la academia (Valera-Ordaz y López-García, 2019), aún son escasas las investigaciones que aborden esta temática en Instagram (Jaramillo-Dent y Pérez-Rodríguez, 2019). Por este motivo, el instrumento de análisis se completó con variables de un trabajo sobre el uso político de Instagram (Quevedo-Redondo y Portalés-Oliva, 2017)

Se consideraron las siguientes variables:

-Formales: formato de la imagen y características de la imagen

-Temáticas o de contenido (Igartua, 2006) para indagar en el imaginario de la infancia. Para ello se indagó respecto de: las personas adultas que acompañan y atestiguan ese período de vida (actores secundarios), los espacios concurridos por los y las niñas/ os durante su infancia (escenarios/contextos de la imagen), las acciones, los juegos y los comportamientos de las y los niñas/os (acción de la protagonista de la imagen), aquellos objetos que hacen a la infancia y a su imaginario (elementos que acompañan 
a la protagonista de la imagen). Asimismo, se incluyeron las variables calidad de la imagen y color de la imagen para identificar el retrato en el pasado de la niñez. Por último, se incorporó la variable dirección de la mirada de la protagonista que evidencia cierta apelación y conexión con el observador (Alexander y Hahner, 2016).

Respecto a los textos recolectados, como no varían significativamente y en su mayoría dicen el @nombredelausuaria a los 11 años \#NiñasNoMadres, sólo se han valorado aspectos formales tales como la presencia hashtags, emoticones y etiquetas para mencionar a otros usuarios.

La codificación fue completada manualmente por las autoras de este artículo. Para garantizar la fiabilidad del análisis una asistente de investigación realizó la codificación con el mismo libro de códigos a partir de una muestra del $20 \%$ de las publicaciones $(n=19)$ que fueron elegidas aleatoriamente. Los coeficientes de Kappa de Cohen y Alfa de Krippendorff fueron utilizados para medir el nivel de acuerdo en la tabulación de los datos (Lombard, Snyder-Duch y Bracken, 2002; Hayes y Krippendorff, 2007). De acuerdo con los resultados (0.88 para el coeficiente Kappa de Cohen (K) y 0.92 para Alpha de Krippendorff" (a), la fiabilidad se consideró alta en el análisis (Hayes \& Krippendorff, 2007; Lombard et al., 2002).

El activismo de celebridades influencia en los temas que se discuten en el espacio público, consiguiendo incidir en la agenda mediática y política, logro difícil de alcanzar por el activismo de ciudadanos (Cox, 2011). La repercusión de la campaña fue evaluada a partir de dos acciones. Por un lado, para medir la interacción que ocurrió dentro de Instagram se contabilizaron las interacciones recibidas en cada posteo: se registraron la cantidad de likes y de comentarios. Esto fue incluido en el libro de códigos. Además, para observar la repercusión que obtuvo la campaña fuera de la red, se rastreó la cobertura de la temática en las páginas de noticias más populares en Argentina (Newman et al., 2019). Esto se completó identificando en Google Trends (Google Trends, 2019) el interés sobre la cuestión que tuvieron los internautas en el espacio digital.

\section{Resultados}

\subsection{Análisis de las imágenes}

En la cuenta de Instagram de @actrices.argentinas, todas las imágenes publicadas durante el período de estudio $(n=89)$ tienen como protagonista a una niña. El 94,38\% de las entradas $(n=84)$ se registraron el 28 de febrero de 2019 y 5,62\% $(n=5)$ el 1 de marzo de 2019.

La campaña cuenta con fotografías $(73 \% n=65)$, fotografías con texto incluido en la imagen $(24,71 \%, n=22)$ y collage de fotos $(2,24 \%, n=2)$. El $88,76 \%(n=79)$ son imágenes a color y el $11,23 \%(n=10)$ son blanco y negro. Del total de las fotografías, el $2,24 \%$ son imágenes de buena calidad, con colores nítidos y buen registro general, que se corresponde con ser imágenes digitales nativas ( $n=3,3,37 \%)$ mientras que el 39,32\% $(n=35)$ tiene una calidad media y el $58,42 \%(n=52)$ de las imágenes son de baja calidad esto es: están fuera de foco, pixeladas y la protagonista aparece con los ojos rojos. Esto se relaciona con que el $96,62 \%(n=86)$ de los posteos visuales que forman parte del corpus de estudio son copias digitales de fotografías reveladas en papel, tal como puede observarse en la imagen 3.

En el $79,77 \%$ ( $n=71$ ) de los casos, la niña se encuentra sola, sin actores secundarios. En el $6,74 \%(n=6)$ de las imágenes publicadas, las niñas aparecen en compañía de adultos, 


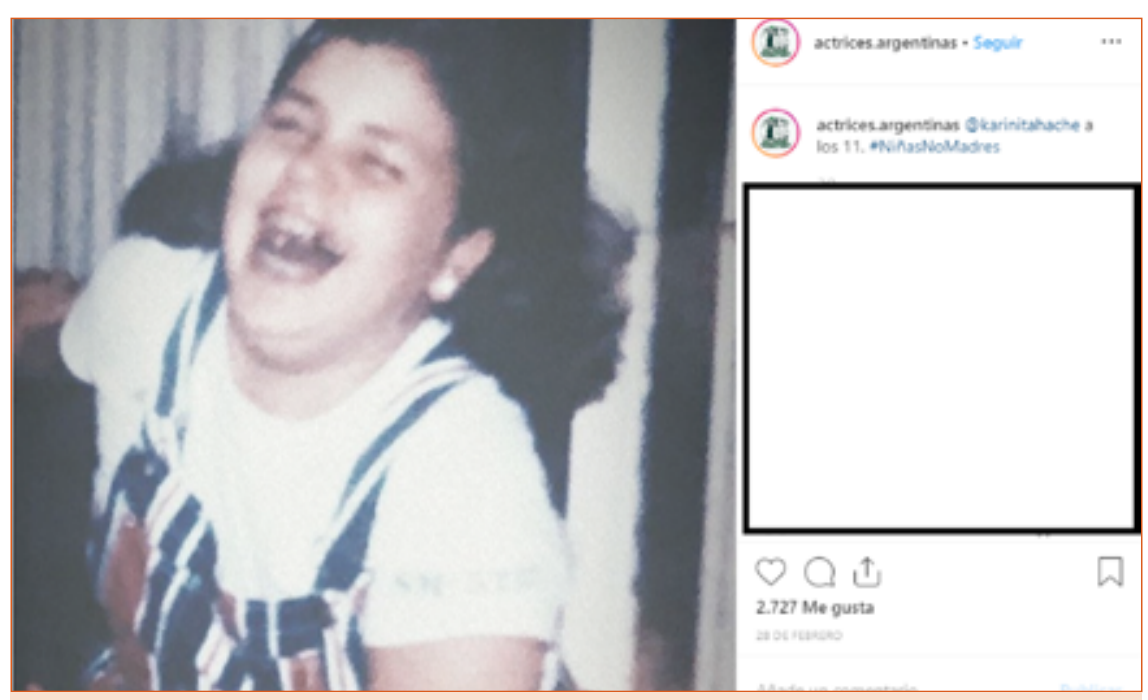

Imagen 3. Ejemplo de posteo con fotografía de baja calidad Fuente: Instagram

y se puede inferir que estos adultos son padres, abuelas y madres de las protagonistas. En todos los casos estos adultos aparecen acompañando, protegiendo en el abrazo esa historia que suele contarse de la infancia, donde los roles de los adultos y de las niñas parecen estar bien delimitados. También se publican imágenes en las que aparece la niña acompañada de otros niños y niñas, y esto ocurre en el $13,50 \%(n=12)$ de los casos, transmitiendo una niñez lúdica que se despliega a partir de mostrar a las niñas en situaciones de juego con sus pares, tal como se ve en la Imagen 4 , y en las que, a falta de explicación, resulta difícil identificar el tipo de juego del que participan.

Al observar los escenarios en los cuales se sitúan las protagonistas, se encuentra que un $32,58 \%(n=29)$ de las imágenes fueron tomadas en la casa. En este caso, las niñas interactúan espontáneamente con el lugar habitado, que se enmarca en la disposición de los objetos que circulan en el imaginario como propios del hogar, como el sillón, la silla, la mesa y los platos para comer. De esta forma, la niñez y lo cotidiano se revelan dentro lo esperable y de aquello que la mirada del internauta puede reconocer.

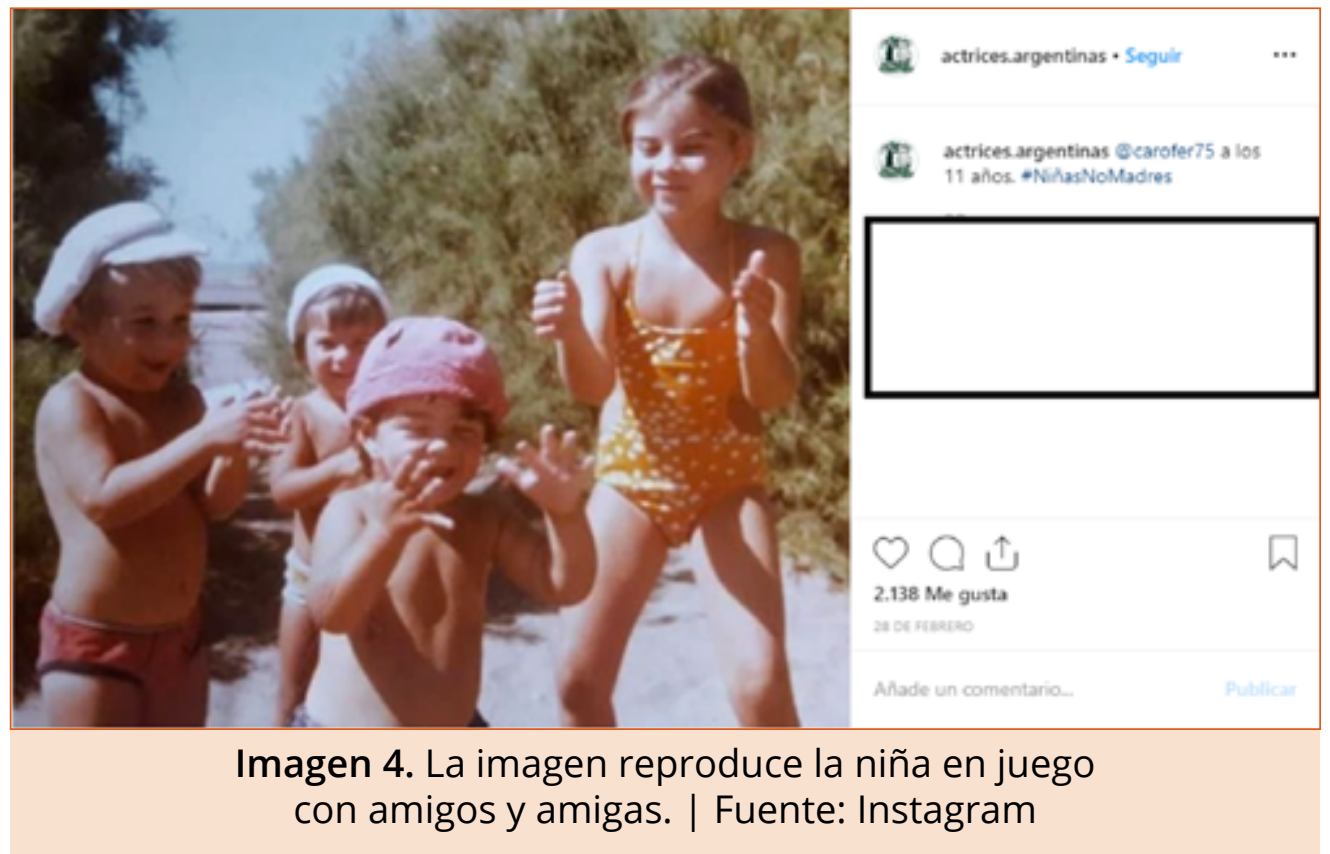


El segundo escenario dominante se configura en un espacio indefinido $(32,48 \%, n=28)$. Esto es muy interesante, puesto que, en la mayoría de los casos, la ausencia de un ámbito concreto se repone con el primer plano sonriente de la niña que ocupa toda la imagen y que puede verse en la Imagen 5.

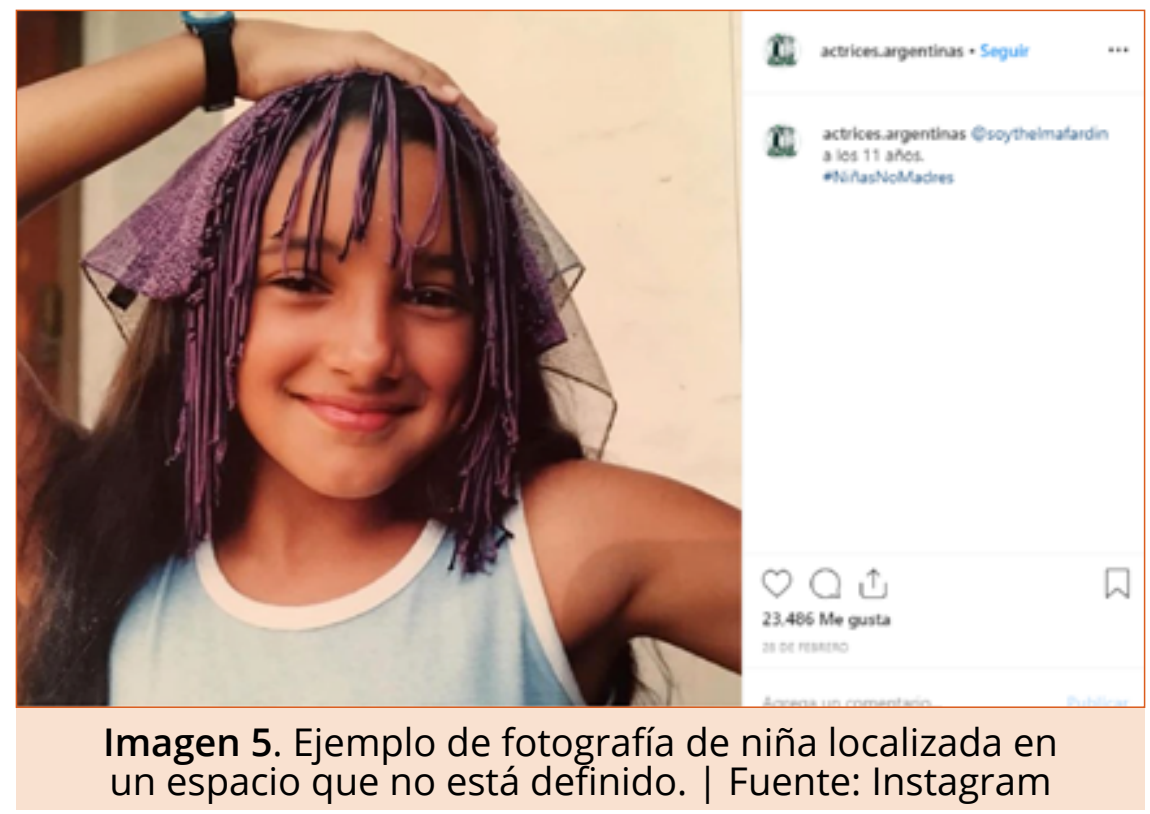

Los espacios verdes se identifican en un $14,6 \%(n=13)$ de las fotos y están directamente relacionados con lo lúdico y con la posibilidad de transitar diversos ámbitos disponibles para esa idea de la niñez plena que se busca generar como efecto y que, desde ya, se opone al rol desplazado de una "niña-madre". Luego aparecen imágenes en la playa $(6,74 \%, n=6)$, en la escuela $(4,49 \%, n=4)$, en la vereda $(3,37 \%, n=3)$, en un escenario teatral $(2,24 \%, n=2)$, en un estudio de fotografía $(2,24 \%, n=2)$, en la montaña $(1,12 \%$, $\mathrm{n}=1)$ y en un carrusel $(1,12 \%, \mathrm{n}=1)$.

En cuanto a los escenarios de menor porcentaje, cabe detenerse en el 4,49\% de las imágenes en las que la niña se encuentra en la escuela. La niña víctima de la historia motivadora de la campaña no asistía a la escuela (Safatle, 2019). En este sentido, las situaciones/historiascontadasenlasimágenesremitenalasituacióndelaniñadeTucumán y evidencian las inequidades observadas en distintos reportes (UNICEF, 2017). En este marco, se destacan las fotografías de las actrices alumnas, con sus uniformes y con sus

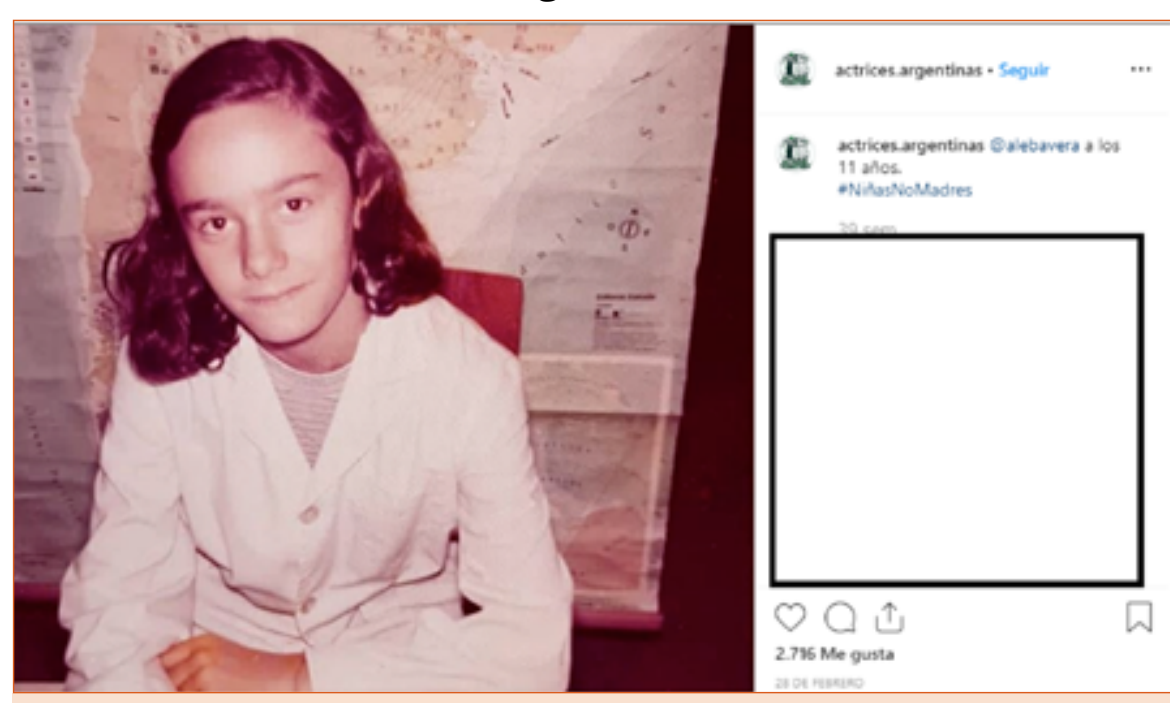

guardapolvos blancos, propios estos últimos de las escuelas públicas de Argentina, tal como se muestra en la imagen ejemplo 6.

Imagen 6. Ejemplo de localización en escuela. | Fuente: Instagram 
En cuanto a las acciones que realizan las protagonistas (no excluyentes en su clasificación para este análisis), las niñas aparecen sonriendo en gran parte de las imágenes que conforman el corpus $(82.02 \%, n=73)$. Esta acción se combina con un $13.48 \%(n=12)$ que se presentan jugando y un $11.23 \%(n=10)$ que lo hacen abrazando.

Un $13.48 \%(n=12)$ de las fotografías muestran a las niñas solo observando y, en menor

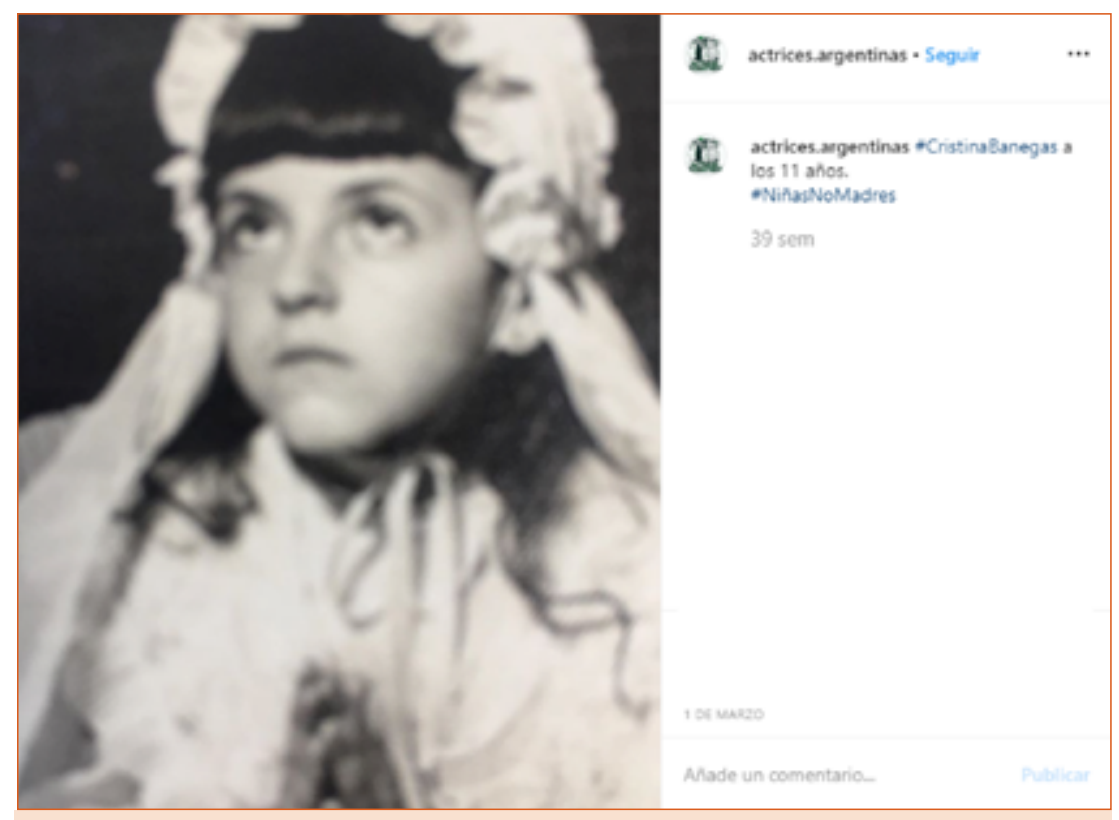

Imagen 7. Cristina Banegas, retratada en su primera comunión, con el hábito que se usaba para identificar esa ceremonia religiosa. | Fuente: Instagram

medida, un 2,24\% $(n=2)$ incorpora el ritual de la comunión como parte de las historias de la infancia, lo que se identifica en \#cristinabanegas y @ soycarocostas, vestidas con el vestido que solía usarse para esta ceremonia (Imagen 7).

Las situaciones de juego $(13,48 \%, \quad n=12)$ exhiben diversos elementos también propios del imaginario de la niñez. El juego con las muñecas aparece retratado en un $2,24 \%(n=2)$. En cuanto a la interacción con muñecos, es muy interesante analizar el provocador post de @lodemarta (Imagen 8) donde se muestra a la niña "jugando" a ser madre con un bebote, trazando un límite entre una escena ficcional sobre la maternidad y la realidad de la situación sobre el evento disparador de la campaña.
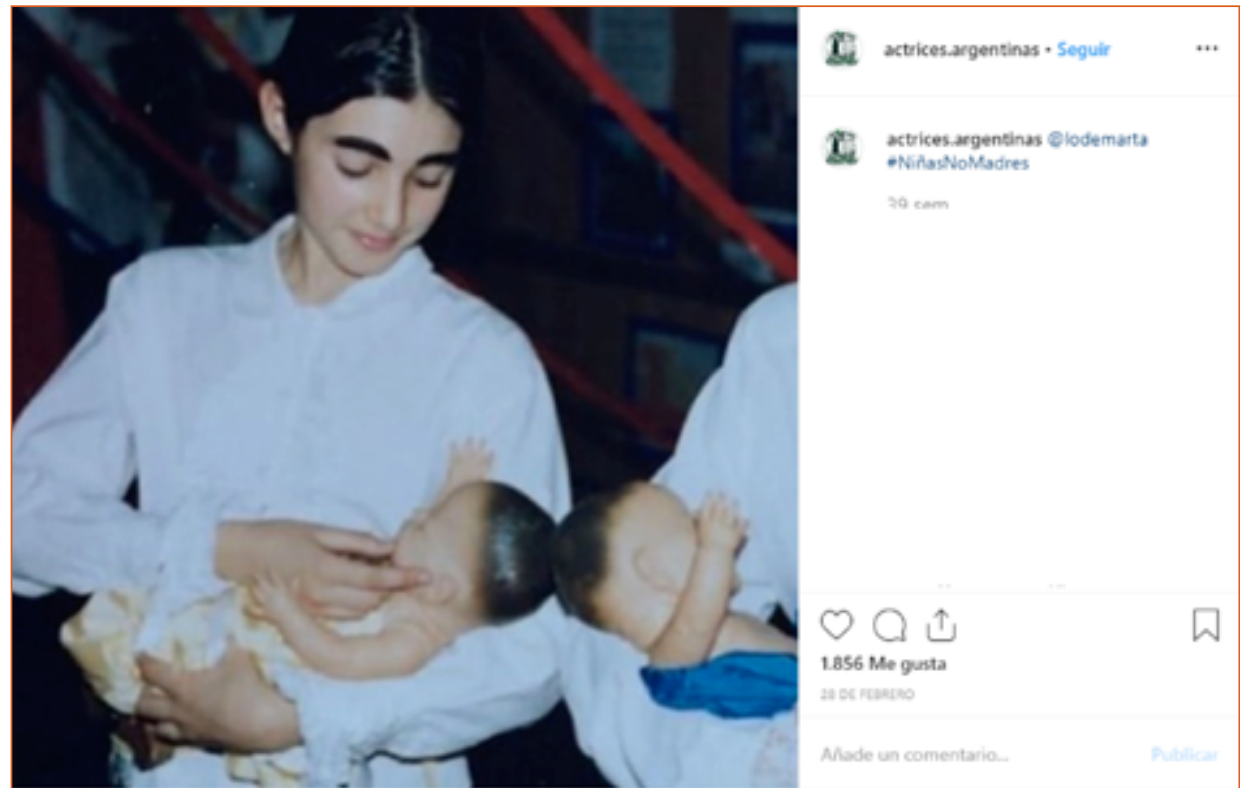

Imagen 8. Esta entrada de @lodemarta la muestra a la actriz de niña jugando a ser mamá, con un muñeco en brazos. | Fuente: Instagram 
La representación del mundo lúdico infantil se completa con escenas de niñas interactuando con sus mascotas en un $4.49 \%(n=4)$. En el $4.49 \%(n=4)$ las niñas están fotografiadas con sus bicicletas. La situación de juego también se combina en un $5.61 \%$ $(n=5)$ con niñas actuando, lo cual traza una identidad directa y resignifica el rol de @ actrices.argentinas.

Por último, en el $82.02 \%(n=83)$ de las imágenes, las niñas se presentan sin elementos. Esto se relaciona directamente con lo analizado en torno a los escenarios indefinidos $(31,46 \%, n=28)$. Estos ámbitos, junto a la falta de elementos, enfatizan los primeros planos de los rostros (Imagen 9). Esto se combina con el hecho de que el $82.02 \%(n=73)$ de esos rostros dirigen su mirada a cámara y solo un $17.97 \%(n=16)$ no lo hace.

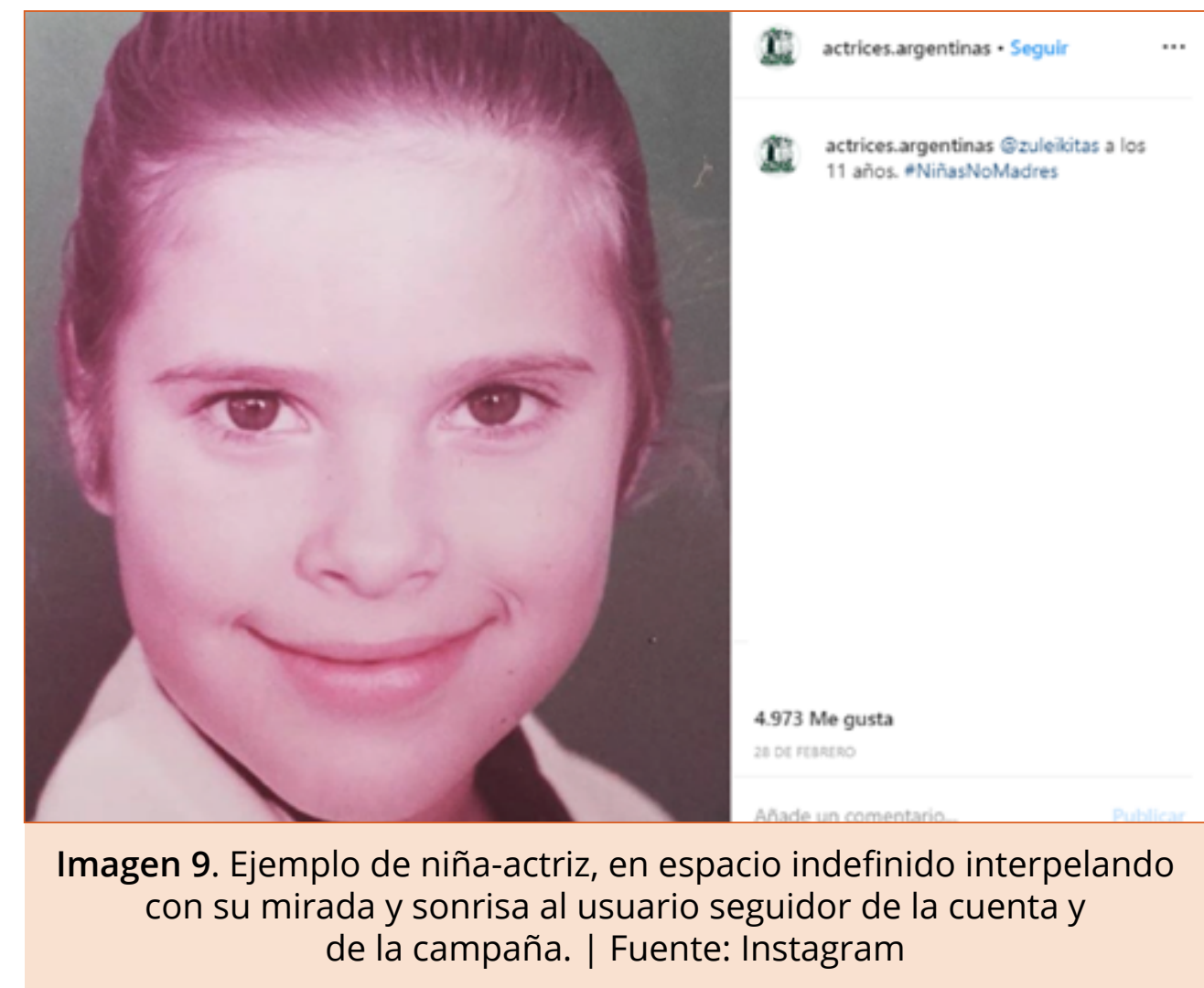

Entonces, al observar estos últimos tres aspectos (el espacio indefinido, la falta de objetos y la mirada a cámara, acompañada de una sonrisa), podemos percibir como efecto principal de las imágenes de la campaña una intencionalidad de detenerse en un rostro pleno de una niña que mira e interpela a quien la observa, recordándole este imaginario de la niñez en oposición a lo vivido por la niña de Tucumán.

\subsection{Análisis de los elementos textuales}

Respecto de los textos que acompañan a las imágenes, el 100\% ( $n=89)$ tienen el hashtag \#NiñasNoMadres.

Las imágenes publicadas parten de la consigna "Yo a los 11 años" y llevan el siguiente texto: @nombredelausuaria a los 11 años. \#NiñasNoMadres. Esta afirmación se repite en el $89 \%$ de las publicaciones $(n=68)$. En el resto de los casos $(11 \%, n=76$, contabilizando una imagen por álbum), los textos, además, incluyen otra información relacionada con el caso disparador de la campaña, como se observa en la imagen 2, de @lolafonca. 
En el $14,60 \%(n=13)$ de las imágenes se incluyeron otros hashtags. Los resultados indican que, en el caso de los álbumes, estos no llevan la etiqueta de la actriz niña de la imagen. Dos cuestiones se observan en el caso de los álbumes: o publican un hashtag para referenciar el lugar de donde proviene la imagen. Así \#ActricesViedmaPatagones se repite en cuatro oportunidades, \#SanLuis también en cuatro, \#RíoNegro en una ocasión, o etiquetan al colectivo al que pertenecen las niñas actrices incluidas en el álbum: @actricesargmisiones, @actrices.neuquen.

Luego aparecen los hashtags \#CristinaBanegas (imagen 6) y \#MirtaBusnelli, dos actrices argentinas que no cuentan con perfiles en Instagram propios.

También aparece, publicado por @lolafonca, \#NoEslleEsTortura (en referencia a la Interrupción Legal del Embarazo -ILE- en la que el embarazo de la niña de Tucumán se encuadraba para ser llevado a cabo, sin embargo, el protocolo no se cumplió, imagen 2). En esta misma línea, se identifica el \#cesareanoesile (cesárea no es ILE) para acompañar el texto. En sólo dos ocasiones se incluye un emoticón que coincide en ser un corazón de color verde, con el que se identifican en las redes las activistas de la Campaña Nacional por el Aborto Legal, Seguro y Gratuito.

\subsection{Repercusión de la campaña}

Al observar el número de las interacciones digitales que la campaña obtuvo en la página de @actrices.argentinas en Instagram, los datos refieren a un total de 452.235 likes y de 3.268 comentarios. Esto indica un promedio de 5950 likes por publicación y 38 comentarios por posteo. Son 21 (27,63\%) las publicaciones que superan este promedio, mientras que las que duplican este promedio son solo cinco actrices: @lolafonca (28.203 likes y 237 comentarios), @lalioficial (38353 likes y 322 comentarios) @emilia_att (14.230 y 250) @soythelmafardin (23.467 likes y 233 comentarios), @julietacardinali (13.704 likes y 254 comentarios). Para situar la concentración de interacciones en estas cinco entradas, podemos rastrear distintas cuestiones.

En este sentido, resulta interesante observar en el espacio digital el interés sobre la temática medida por Google Trends: el interés por el \#NiñasNoMadres tiene tres picos de interés: del 27 de enero al 2 de febrero de 2019, período que concuerda con otro caso de características similares (Centenera, 2019b). Además, el 1 de febrero, se publica la editorial de La Nación (La Nacion, 2019a). El siguiente período de mayor interés coincide con los días de la campaña de @actrices.argentinas. (Imagen 10).

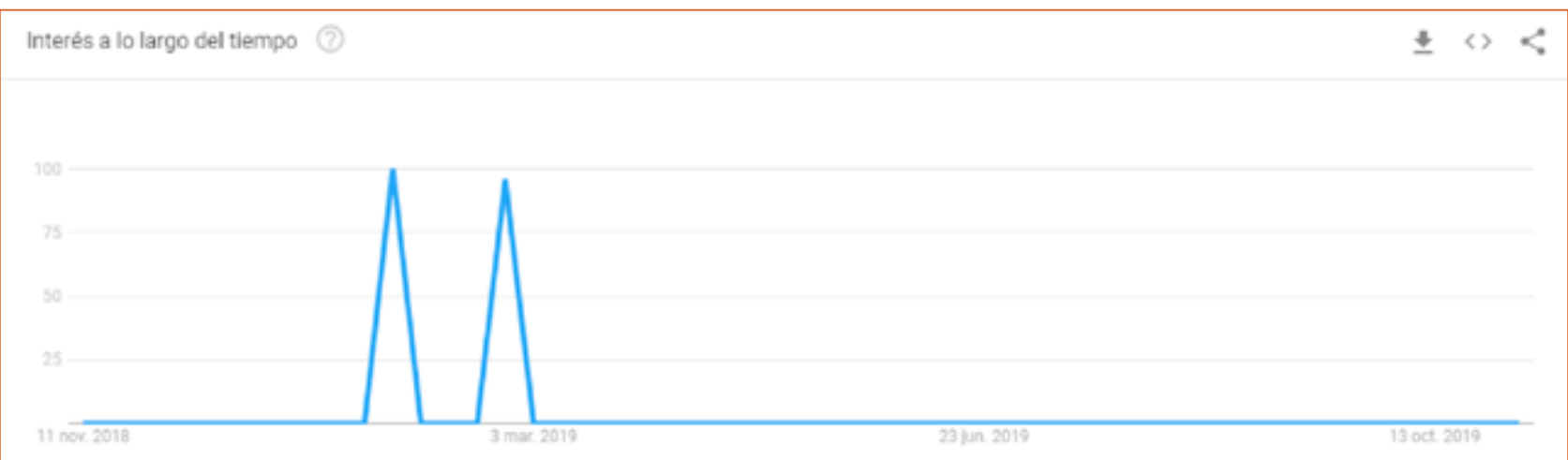

Imagen 10. Interés de los internautas sobre \#NiñasNoMadres. | Fuente Google Trends 
En cambio, si se cambia el criterio de búsqueda y se rastrea el mismo hashtag, pero solo las búsquedas de imagen, todo el interés se concentra en los días de la campaña, esto es 28 de febrero de 2019 y 1 de marzo de 2019 (Imagen 11).

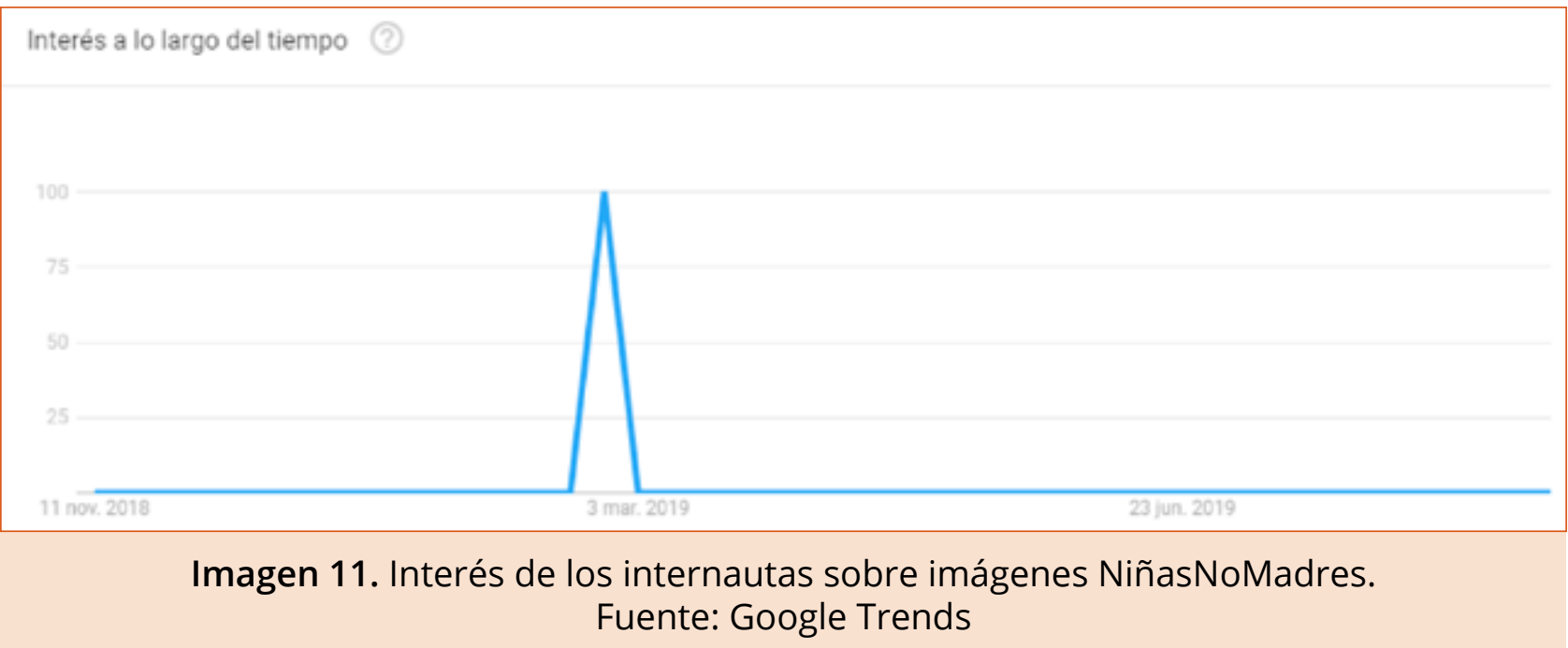

La campaña tuvo repercusión en los principales medios digitales de Argentina. El mismo día, el 28 de febrero, Infobae.com, la plataforma de noticias más consumida en Argentina (Newman et al., 2019), dio cuenta del accionar de @actricesargentinas y tituló "Niñas no madres: las famosas postearon fotos a sus 11 años por el caso de la nena violada en Tucumán" (Infobae, 2019b). Por su parte, el diario Clarín con el titular "\#NiñasNoMadres: una consigna viral para repudiar la cesárea a la nena de 11 años violada en Tucumán" cubrió la noticia (Clarín, 2019), mientras que La Nación se sumó con "Por qué las famosas comenzaron a compartir fotos suyas a los 11 años en las redes" (La Nación, 2019b). En los tres casos, se realiza una síntesis del caso, se destaca la relevancia del Colectivo Actrices Argentinas y se adjuntan varios posteos de la campaña.

Por su parte, el 1 de marzo, pagina12.com.ar solo utilizó el hashtag para titular su nota (Página/12,2019b). Finalmente, el 2 de marzo, tn.com.ar presenta una nota titulada "Niñas, no madres" escrita por Raquel Vivanco, columnista invitada, quien preside el Observatorio Ahora Que Sí Nos Ven y es referente de Marea, un movimiento feminista, popular y disidente (Vivanco, 2019).

\section{Discusión y conclusiones}

Este trabajo estudió el uso de hashtivismo feminista \#NiñasNoMadres, impulsado por el colectivo @actrices.argentinas en la red social Instagram con el fin de ubicar el funcionamiento de este repertorio de activismo digital y el rol de la imagen en la narración y difusión de microhistorias de movilización (Fina \& Georgakopoulou, 2012; Giaxoglou, 2018; Ofori-Parku y Moscato, 2018). Con respecto a la RQ1, los resultados indican que el \#NiñasNomadres fue acompañado por imágenes de las actrices en su niñez, en su gran mayoría fotografías de baja o mediana calidad porque fueron tomadas cuando aún las cámaras digitales no estaban en el mercado. Estas fueron digitalizadas para su inclusión en la campaña, ya que Instagram opera, en la totalidad de sus funciones, en teléfonos móviles para tomar, editar y compartir imágenes entre los seguidores. Tal es así que las únicas tres fotografías digitales incluidas en la campaña (@lalioficial, @soythelmafardin y @dedominicieva) resaltan por su nitidez y diafanidad. Sin embargo, las imágenes que prevalecen en la campaña fueron tomadas décadas atrás durante la niñez de las actrices y parecen haber sido editadas con el uso de los 
filtros para lograr un efecto de fotografía tomada por cámara analógica. De este modo, son imágenes que logran el efecto de pasado porque justamente fueron tomadas en ese tiempo. En este sentido, son imágenes que desde la nostalgia de la infancia pasada conectan con un público afectivo (Papacharissi, 2015) que recorre el muro colectivo de celebridades en busca de un activismo de novedosos repertorios (Jenkins et al., 2018).

Al retomar la definición de infancia sobre la cual se realizó el análisis (UNICEF, 2005), observamos que las imágenes dan cuenta de espacios propios de ese concepto de infancia: la escuela, la casa y los lugares de recreo como la vereda, la playa, los espacios verdes, las plazas con su carrusel, como así también momentos de esta etapa: las vacaciones, los juegos con muñecos, la interacción con las mascotas, los paseos en bicicleta, la ceremonia de la comunión. Las imágenes que conforman la campaña suman además a los actores que acompañan esa infancia: padres, amigos, abuelos, compañeros de clase, quienes son los que conforman, dice UNICEF (2005) la comunidad que rodea a la niñez para estimular y dar amor. Y en estos espacios, con estos momentos, las publicaciones logran que el usuario seguidor de la cuenta se sumerja en la familiaridad lejana en el tiempo de las actrices a partir de una pantalla íntima que se transforma en movilizadora, activa e implicante. Y es en este punto donde la instantaneidad y temporalidad de las prácticas que Instagram admite (sólo pueden subirse imágenes tomadas por el teléfono móvil que indican un aquí y ahora), en la campaña mutan a un allá y entonces, el de la infancia, que narra el pasado en microhistorias, en una aplicación cuyas performances privilegian el presente.

Respecto de la RQ2, los textos que acompañan al \#NiñasNoMadres son repetitivos en la gran mayoría de los casos, porque la narración, el storytelling (Jenkins, Lashley y Creech, 2017) es llevado a cabo por medio de la imagen: el hashtivismo feminista \#NiñasNoMadres logra conectar a partir de una narrativa conjunto texto-imagen, y en este diálogo obtiene forma la campaña y la historia. Así, la convergencia del hashtag y de la imagen de las niñas de 11 años que provienen de un espacio íntimo y privado del pasado, se resignifican en el escenario digital demostrando cómo lo personal es político (Hanisch, 1969). Por otro lado, la pantalla íntima de Instagram, relacionada con la promoción del self (Alexander \& Hahner, 2016; Khoja-Moolji, 2015), muta en un medio de vehiculización de causas políticas (Eldin, 2016; Tarullo, 2019a), a partir de un colectivo feminista, las actrices argentinas, que, con otras herramientas, cuentan una microhistoria, personal e íntima que se convierte en pública, política, de visibilización y protesta (Fina \& Georgakopoulou, 2012).

A diferencia de estudios anteriores en los cuales el hashtag contiene la microhistoria (Ofori-Parku y Moscato, 2018), este estudio da cuenta de que este diálogo imagenhashtag es el que narra una microhistoria del pasado (Page, 2012) y este binomio sostiene la historia, la historia de la niñez. La microhistoria es la que cuenta la imagen aferrada al hashtag: una niña de 11 años juega con su perro, sonríe, abraza a su padre, se sienta sobre la falda de su abuela, posa para la cámara con su madre. Una niña de 11 años anda en bicicleta, se divierte con sus amigos, se disfraza para ser actriz y va a la escuela. Una niña de 11 años estudia y también alza y mece en sus brazos a un bebote, que es muñeco, no un hijo. Todo porque una niña de 11 años es niña, no es madre, dicen las microhistorias contenidas en imágenes/hashtags.

El contraste del imaginario idealizado contado por las imágenes se desnaturaliza a través del \#NiñasNoMadres, puesto que este rompe la obviedad sobre lo esperado en la niñez y señala que esa imagen que allí se propone entra en tensión con la experiencia 
real de las niñas-madres (UNICEF, 2005, 2017). El \#NiñasNoMadres trae, a partir de la imagen, las voces e historias de reportes estadísticos que dan cuenta de inequidades que viven las niñas en Argentina y en América Latina (UNICEF, 2017) y que se condensan en la niña de Tucumán que da origen a la campaña, pero que se replican en otras situaciones. En efecto, esta campaña da cuenta de ello al incorporar otros hashtags como \#cesareanoesile (cesárea no es interrupción legal del embarazo), poniendo en conversación temáticas de debate en Argentina. Es la participación activa de las actrices lo que visibiliza estas demandas ante otros públicos, ya que cuentan desde un lugar, un lenguaje y una estética distintos a las prácticas de los actores políticos institucionalizados.

Asimismo, y respondiendo también a la RQ2, el texto que acompaña a \#NiñasNoMadres al ser la etiqueta -cuenta en Instagram- de la actriz, por ejemplo @lalioficial a los 11 años, sirve para contextualizar la imagen. Una cuestión que es preciso considerar en esta discusión es el uso del hashtag en lugar de la etiqueta en el caso de las actrices que no tienen cuenta en Instagram (\#cristinabanegas y \#mirtabusnelli) y también cuando la entrada es un álbum de colectivos de actrices oriundas de distintas localidades (\#San Luis, \#ActricesViedmaPatagones y \#RioNegro). Aquí, se observa un uso de este recurso como identificación, es decir para situar al autor en relación con las interacciones que él mismo protagoniza en la red (Daer et al., 2014).

La campaña en Instagram instala y visibiliza un tema político ante un público distinto al de los medios tradicionales. En este sentido, el \#NiñasNoMadres permite, respondiendo a la RQ3, al menos dos situaciones. Por un lado, la amplificación de la difusión de causas sociopolíticas a partir de formatos no convencionales de participación (Bonilla \& Rosa, 2015) y de la adhesión a un hashtag-postulado en su función de movilización (Daer et al., 2014). Además, al provenir de la cuenta de Instagram de actores políticos/ as no institucionalizados (@actrices.argentinas), logran otra conexión con el público heredada de otros espacios, otras performances y otras relaciones, donde la celebridad de las autoras de la campaña da cuenta (Kwon, 2019).

Respecto de la RQ3, sobre rol que cumplen las actrices en colectivo en el hashtivismo feminista para alcanzar una mayor visibilización sobre la campaña, resultó interesante observar que el activismo digital de @actrices.argentinas reconfigura las expectativas que se producen en torno a la idea de celebridad, al activar la movilización desde un espacio colectivo antes que individual. De alguna manera, @actrices.argentinas se suma a demandas que exceden su propio espacio de acción para conectarse con otras organizaciones y ocupar un lugar novedoso en el entorno digital reciente en relación a las figuras del espectáculo. Podría decirse que se construyen como un interlocutor y un intermediario entre los ciudadanos, sobre todo los más jóvenes, y los poderes políticos y mediáticos sobre causas políticas urgentes.

En este sentido, cinco entradas concentran casi el 30\% de las interacciones durante la campaña. Al respecto, es preciso tener en cuenta ciertas situaciones que parecen responder a estos resultados. @lalioficial es de todas las actrices que protagonizaron la campaña, la que más seguidores tiene en la red social en estudio, superando los seis millones y medio de fans en Instagram. Le sigue @emilia_att, con más de un millón trescientos mil seguidores en la plataforma visual. Por su parte, @soythelmafardin es también una de las actrices más populares en Instagram, en 2018 denunció por violación al conocido actor Juan Darthés, sobre quien ya pesaban otras denuncias de acoso, denuncia que dio lugar a la campaña digital \#miracomonosponemos, en referencia a la frase que la actriz confesó haber escuchado de Darthés durante el evento denunciado 
(TN, 2018; Perfil,2018). Una tercera razón se ubica en el protagonismo que algunas actrices tienen en el colectivo, en su rol de activistas y difusoras. Aquí ubicamos en alguna medida a @julietacardinali, pero más intensamente a @lolafonca, quien inicia la campaña en la cuenta del colectivo, y además es la que acompaña a la Campaña Nacional por el Aborto Legal Seguro y Gratuito en todos los pasos que dio durante el debate y tratamiento en el Congreso Nacional.

Respecto de la repercusión que la campaña \#NiñasNoMadres tuvo por fuera de Instagram, los resultados de este estudio dan muestra del impacto que tuvo esta performance de activismo digital en los principales medios periodísticos de Argentina: la cuestión de la celebridad resultó ser fundamental en pos de la sensibilización y la visibilización sobre el tema por fuera de Instagram (Fuqua, 2011; Huliaras y Tzifakis, 2015; Kwon, 2019). También este esquema se hizo evidente en el interés de los internautas, que buscaron en el espacio digital el \#NiñasNoMadres, acción online que se concentró en la búsqueda de imágenes en el mismo momento en el cual la campaña comenzaba a circular en Instagram. Esta incidencia y la implicancia expresada en interacciones fue posible en parte por las microhistorias contadas en las imágenes que acompañaron al hashtivismo feminista protagonizado por actrices famosas, que en colectivo protagonizaron un activismo de celebridades, capaces de captar la atención de los más jóvenes (Cox, 2011), permitiendo una amplificación de las demandas, logro que el ciudadano difícilmente pueda alcanzar (Cox, 2011; Kwon, 2019).

Este trabajo no está exento de limitaciones. Por un lado, si bien Instagram es la red social favorita de los grupos poblacionales más jóvenes (INDEC, 2018; Kemp, 2018) y los movimientos feministas en Argentina son más activos en esta plataforma (Tarullo, 2019a, 2019b), conocer los flujos de esta campaña en otras redes sociales, en especial en Twitter, que es un espacio destinado a conversaciones sobre temáticas de interés público (Bruns y Burgess, 2011), permitiría indagar y comparar qué ocurre con la campaña \#NiñasNoMadres pero en este caso en un escenario digital donde lo que prima no es la imagen, como es el caso de Instagram, sino la conversación e interacción entre los usuarios. Además, en futuras investigaciones podría estudiarse esta campaña en relación con la promoción del self (Moon et al., 2016) y la conexión de las celebridades con su público afectivo (Papacharissi, 2015).

Además, para comprender en profundidad este activismo colectivo de las actrices, examinar el activismo de las celebridades en sus cuentas personales de Instagram colaboraría en aclarar y ahondar en estas performances colectivas de activismo de celebridades (Gámez Fuentes, Gómez Nicolau y Maseda García, 2016; Fuqua, 2011; Huliaras y Tzifakis, 2015; Ellcessor, 2018; Kwon, 2019). Por otra parte, las interacciones que permitieron medir la repercusión de la campaña dentro la plataforma precisaría de otras metodologías que permitan analizar el alcance de la campaña más allá de la cuenta @actrices.argentinas, indagando en la función de movilización del hashtag (Daer et al., 2014) por fuera de este espacio colectivo digital.

\section{Referencias}

Acosta, M. y Nevache, C. (2020): "La conversación digital en torno al hashtag RespetoAIDolorDeMadre en Panamá", Dígitos. Revista de Comunicación Digital, n6, pp. 13-30.

Alexander, K.P.yHahner, L. A. (2016): "The IntimateScreen : Revisualizing Understandings of Down Syndrome Through Digital Activism on Instagram". En Walls, D. y Vie, S. (eds): Social Writing/Social Media: Pedagogy, Presentation, and Publics. Washington: WAC Clearinghouse, pp. 225-243. 
Agencia de Noticias RedAcción (2019): "Amplio repudio de las y los trabajadores de La Nación al editorial de hoy", Agencia de Noticias RedAcción (1 de febrero). Recuperado de: https://www.anred.org/2019/02/01/amplio-repudio-de-las-y-los-trabajadores-dela-nacion-al-editorial-de-hoy/ [Consulta: 28 de noviembre de 2019]

Ambito (2018): "Qué es y cómo surgió el colectivo Actrices Argentinas", Ambito.com, (12 Septiembre). Recuperado de: https://www.ambito.com/que-es-y-como-surgio-elcolectivo-actrices-argentinas-n5054127. [Consulta: 28 de noviembre de 2019]

Annunziata, R. et al. (2016): "Argentina", in Sorj, B. y Fausto, S. (eds) Activismo político en tiempos de Internet. San Pablo: Edições Plataforma Democrática, pp. 37-112.

Aruguete, N. y Koziner, N. (2014): "La cobertura mediática del" 7D" en la prensa argentina.", Disertaciones, vol. 1, n 7 , pp. 129-165.

Bonilla, Y. y Rosa, J. (2015): "\#Ferguson: Digital protest, hashtag ethnography, and the racial politics of social media in the United States", en American Ethnologist, vol. 42, pp. 4-17. doi: 10.1111/amet.12112.

Bruns, A. y Burgess, J. (2011): "The use of Twitter hashtags in the formation of ad hoc publics", en 6th European Consortium for Political Research General Conference (ECPR 2011), (Agosto), pp. 1-9.

Castells, M. (2012): Redes de Indignación y esperanza. Edited by Gedisa. Barcelona: Alianza Editorial.

Centenera, M.(2019a): "Elcalvario de una niñavioladaque intentabaabortarenArgentina”, El país, (28 Marzo). Recuperado de: https://elpais.com/sociedad/2019/03/26/ actualidad/1553601793_174624.html. [Consulta: 20 de noviembre de 2019]

Centenera, M. (2019b): “Una niña argentina de 12 años que fue violada y cuya madre pidió un aborto da a luz por cesárea", El País (19 Enero). Recuperado de: https://elpais. com/sociedad/2019/01/18/actualidad/1547836652_224879.html. [Consulta: 20 de noviembre de 2019]

Chenou, J. M. y Cepeda-Másmela, C. (2019): “\#NiUnaMenos: Data Activism from the Global South”, en Television and New Media, vol. 20, n² 4, pp. 396-411. doi: 10.1177/1527476419828995.

Clarín (2018): "\#Miracomonosponemos: La fuerte denuncia de Thelma Fardin", en Clarín (11 de diciembre). Recuperado de: https://www.clarin.com/sociedad/ miracomonosponemos-fuerte-denuncia-thelma-fardin_3_1BTRUuhH5.html. [Consulta: 20 de noviembre de 2019]

Clarín (2019): "\#NiñasNoMadres: una consigna viral para repudiar la cesárea a la nena de 11 años violada en Tucumán", Clarín, (28 de febrero). Recuperado de https://www. clarin.com/sociedad/ninasnomadres-consigna-viral-repudiar-cesarea-nena-11-anosviolada-tucuman_0_xGUOkf76H.html. [Consulta: 28 de noviembre de 2019]

Clark-Parsons, R. (2018): "Building a digital Girl Army: The cultivation of feminist safe spaces online", en New Media and Society, vol. 20, n 6, pp. 2125-2144. DOI: 10.1177/1461444817731919.

Clark, R. (2016): "Hope in a hashtag": the discursive activism of \#WhylStayed", en Feminist Media Studies, vol. 16, nº 5, pp. 788-804. DOI: 10.1080/14680777.2016.1138235.

Cornet, V. (2018): "Instagram Power Users and their Effect on Social Movements", en Indiana University, Purdue University Indianapolis. Disponible en: https://www. semanticscholar.org/paper/Instagram-Power-Users-and-their-Effect-on-SocialCornet-Hall/e32fdd8e5b1dad0bf2d91a8e23019e2c03b695a4\#citing-papers 
Cox, B. (2011): Campaigning for International Justice. pp 1-94. Disponible en: https:// es.scribd.com/document/373709438/Campaigning-for-International-JusticeBrendan-Cox-May-2011

Daer, A. R., Hoffman, R. y Goodman, S. (2014): "Rhetorical Functions of Hashtag Forms! Across Social Media Applications", en Communication Des. Quart. Review, vol: 3, $n^{\circ} 4$, pp. 12-16. DOI: 10.1145/2721882.2721884

Delfino, G., Beramendi, M. y Zubieta, E. (2019): “Participación social y política en Internet y brecha generacional", en Revista de Psicología, vol: 37, n 1, pp. 195-216. doi: 10.18800/psico.201901.007.

El despape web (2018): “Lali Espósito lució el pañuelo verde en la previa de los Grammy Latinos 2018", Infobae, (15 Noviembre). Recuperado de: https://www.infobae.com/ teleshow/infoshow/2018/11/15/lali-esposito-lucio-el-panuelo-verde-en-la-alfombraroja-de-los-latin-grammys/.

Eldin, A. K. (2016): "Instagram Role In Influencing Youth Opinion In 2015 Election Campaign In Bahrain", European Scientific Journal, ESJ, vol: 12, n² 2, p. 245. doi: 10.19044/esj.2016. v12n2p245.

Ellcessor, E. (2018) "One tweet to make so much noise": Connected celebrity activism in the case of Marlee Matlin", en New Media and Society, vol: 20, n 1, pp. 255-271. doi: $10.1177 / 1461444816661551$.

Fileborn, B. y Loney-howes, R. (2019): \#MeToo and the Politics of Social Change, Australia: Palgrave Macmillan. doi: 10.1007/978-3-030-15213-0.

Fuqua, J. V. (2011): "Brand Pitt: Celebrity activism and the Make It Right Foundation in post-Katrina New Orleans", en Celebrity Studies, vol: 2, $\mathrm{n}^{\circ} 2$, pp. 192-208. doi: 10.1080/19392397.2011.574872.

Gámez Fuentes, M. J., Gómez Nicolau, E., \& Maseda García, R. (2016): Celebrities, violencia de género y derechos de las mujeres: ¿hacia una transformación del marco de reconocimiento? En Revista Latina de Comunicación Social, vol. 71, pp. 833-852. https://doi.org/10.4185/RLCS-2016-1123

Georgakopoulou, A. (2017): "Sharing the moment as small stories", en Narrative Inquiry. John Benjamins Publishing Company, vol: 27, n² 2, pp. 311-333. doi: 10.1075/ ni.27.2.06geo.

Gherardi, N. and Gebruers, C. (2015): "El aborto legal en Argentina: la justicia después de la sentencia de la Corte Suprema de Justicia en el caso "F.A.L.", en Seire Documentos REDAAS, 3, pp. 1-36.

Giannoulakis, S.y Tsapatsoulis, N. (2016): "Evaluating the descriptive power of Instagram hashtags", en Journal of Innovation in Digital Ecosystems. Elsevier B.V., vol: 3, n² 2, pp. 114-129. doi: 10.1016/j.jides.2016.10.001.

Giaxoglou, K. (2018): "\#JeSuisCharlie? Hashtags as narrative resources in contexts of ecstatic sharing", en Discourse, Context and Media. Elsevier Ltd, vol. 22, pp. 13-20. doi: 10.1016/j.dcm.2017.07.006.

Google Trends (2019): Google Trends. Recuperado de: https://trends.google.com.ar/ trends/?geo=AR. [Consulta: 28 de noviembre de 2019]

Hanisch, C. (1969): "The personal is political". Recuperado de: http://www.carolhanisch. org/CHwritings/PIP.html. [Consulta: 28 de noviembre de 2019] 
Hayes, A. F. y Krippendorff, K. (2007) "Answering the Call for a Standard Reliability Measure for Coding Data", Communication Methods and Measures. Taylor \& Francis Group, vol: 1, n 1, pp. 77-89. doi: 10.1080/19312450709336664.

Huliaras, A. y Tzifakis, N. (2015) "Personal connections, unexpected journeys: U2 and Angelina Jolie in Bosnia", Celebrity Studies. Routledge, vol: 6, $n^{\circ}$ 4, pp. 443-456. doi: 10.1080/19392397.2015.1087210.

INDEC (2018) Accesos a Internet. Buenso Aires. Recuperado de: www.indec.gob.ar/ calendario.asp [Consulta: 20 de noviembre de 2019]

Infobae (2018): "Las actrices argentinas volvieron a reclamar por la legalización del aborto en el Teatro Cervantes", en Infobae, (30 Abril). Recuperado de: https://www. infobae.com/teleshow/infoshow/2018/07/30/las-actrices-argentinas-volvieron-areclamar-por-la-legalizacion-del-aborto-en-el-teatro-cervantes/. [Consulta: 28 de noviembre de 2019]

Infobae (2019a): "Murió la bebé de la nena de 11 años violada en Tucumán a la que se le había practicado una cesárea", Infobae, (8 Marzo). Recuperado de: https://www. infobae.com/sociedad/2019/03/08/murio-la-bebe-de-la-nena-de-11-anos-violadaen-tucuman-a-la-que-le-habian-practicado-una-cesareal. [Consulta: 28 de noviembre de 2019]

Infobae (2019b):"'"Niñas no madres": las famosas postearon fotos a sus 11 años por el caso de la nena violada en Tucumán", Infobae, (28 Febrero). Recuperado de: https:// www.infobae.com/teleshow/infoshow/2019/02/28/ninas-no-madres-las-famosaspostearon-fotos-a-sus-11-anos-por-el-caso-de-la-nena-violada-en-tucuman/. [Consulta: 15 de noviembre de 2019]

Infocielo (2019): "\#NiñasNoMadres: Repudio en las redes a una nota de La Nación que reivindica la maternidad forzada", Infocielo, (1 de febrero). Recuperado de: https:// infocielo.com/nota/101105/ninasnomadres-repudio-en-las-redes-a-una-nota-de-lanacion-que-reivindica-la-maternidad-forzada/. [Consulta: 28 de noviembre de 2019]

Jaffe, S. (2018): “The collective power of \#MeToo", en Dissent. Foundation for the Study of Independent Social Ideas, vol: 65, n 2, pp. 80-87. doi: 10.1353/dss.2018.0031.

Jenkins, H. (2017): “How a Group of Harry Potter Fans Became Social Activists”, en Culture Jamming Activism and the Art of Cultural Resistance. New York: New York University Press, pp. 133-160.

Jenkins, H. et al. (2018): Any Media Necessary: Mapping Youth and Participatory Politics. New York: NYUPress.

Jenkins, H., Lashley, M. y Creech, B. (2017): "Voices for a New Vernacular: A Forum on Digital Storytelling Interview with Henry Jenkins", en International Journal of Communication, vol. 11, pp. 1061-1068.

Jones, H. y Soltren, J. (2005): “Facebook: Threats to privacy", Project MAC: MIT Project pp. 1-76. Recuperado de: http://ocw.fudutsinma.edu.ng/courses/electrical-engineeringand-computer-science/6-805-ethics-and-the-law-on-the-electronic-frontier-fall-2005/ projects/facebook.pdf [Consulta: 28 de noviembre de 2019]

Kemp, S. (2018): Digital in 2018. Essencial insights into Internet, social meida, mobile and e-commerce use around the world. Recuperado de: https://wearesocial.com/globaldigital-report-2019 [Consulta: 15 de noviembre de 2019]

Khoja-Moolji, S. (2015): "Becoming an "intimate publics": Exploring the affective intensities of hashtag feminism", en Feminist Media Studies, vol: 15, n² 2, pp. 347-350. doi: 10.1080/14680777.2015.1008747. 
Kulkarni, A. (2017): "Internet meme and Political Discourse: A study on the impact of internet meme as a tool in communicating political satire", en Journal of Content, Community \& Communication, vol.6, pp.13-17. doi: 10.2139/ssrn.3501366

Kwon,J.(2019): "Between Hyorishand Hyorism:AKoreanTVStarandSocial MediaActivism”, Television and New Media, vol: 20, n³, pp. 241-256. doi: 10.1177/1527476417742519.

Larkin, K. G. (2009): "Star Power: Models for Celebrity Political Activism”, en Virginia Sports and Entertainment Law Journal, vol: 9, n 1, pp. 155-180. Disponible en: https:// heinonline.org/HOL/LandingPage?handle=hein.journals/virspelj9\&div=7\&id=\&page=

Larrondo, A., Morales-i- Gras, J. and Orbegozo-Terradillos, J. (2019): “Feminist hashtag activism in Spain: measuring the degree of politicisation of online discourse on \# YoSíTeCreo , \# HermanaYoSíTeCreo , \# Cuéntalo y \# NoEstásSola", en Comunicación y Sociedad, vol: 32, nº 4 pp. 207-221. doi: 10.15581/003.32.4.207-221.

Laudano, C. (2018): “\#abortolegal:el grito que tiñó las redes" en Bordes. Revista de Política, Derecho y Sociedad, pp. 1-9.

La Nacion(2019a)“Niñas madres con mayúsculas”, La Nación, (1 Febrero). Recuperado de: https://www.lanacion.com.ar/opinion/ninas-madres-con-mayusculas-nid2216199. [Consulta: 15 de noviembre de 2019]

La Nación (2019b) "Por qué las famosas comenzaron a compartir fotos suyas a los 11 años en las rede", La Nación, (28 Febrero). Recuperado de: https://www.lanacion. com.ar/espectaculos/personajes/yo-11-campana-famosas-cesarea-practicada-nenanid2224317. [Consulta: 28 de noviembre de 2019]

Leaver, T., \& Highfield, T. (2018): Visualising the ends of identity : pre-birth and postdeath on Instagram. Information, Communication \& Society, vol: 21, n¹, pp.30-45. https://doi.org/10.1080/1369118X.2016.1259343

Loader, B. D. y Vromen, A. (2015) "Performing for the young networked citizen ? Celebrity politics, social networking and the political engagement of young people", en Media Culture \& Society, (February 2016), vol.38, pp. 1-20. doi: 10.1177/0163443715608261.

Lombard, M., Snyder-Duch, J. y Bracken, C. C. (2002): “Content Analysis in Mass Communication: Assessment and Reporting of Intercoder Reliability", en Human Communication Research. John Wiley \& Sons, Ltd (10.1111), vol: 28, nº 4, pp. 587-604. doi: 10.1111/j.1468-2958.2002.tb00826.x.

Mahoney, J., Feltwell, T., Ajuruchi, O., \& Lawson, S. (2016): “Constructing the Visual Online Political Self : An Analysis of Instagram Use by the Scottish Electorate", en Politics on Social Media. San José, CA. DOI: 10.1145/2858036.2858160

Martín García, M. T., \& Martínez Solana, M. Y. (2019): “Mujeres ilustradoras en Instagram: Las influencers digitales más comprometidas con la igualdad de género en las redes sociales", en Revista Internacional de Cultura Visual, vol: 6, n² 2. Disponible en: https:// journals.epistemopolis.org/index.php/imagen/article/view/1889

Meraz, S. y Papacharissi, Z. (2013): “Networked Gatekeeping and Networked Framing on \#Egypt", en The International Journal of Press/Politics, vol: 18, n 2, pp. 138-166. doi: 10.1177/1940161212474472.

Moon, J. H. et al. (2016) "The role of narcissism in self-promotion on Instagram", en Personality and Individual Differences. Elsevier Ltd, vol.101, pp. 22-25. doi: 10.1016/j. paid.2016.05.042.

Myles, D. (2019): "Anne goes rogue for abortion rights!": Hashtag feminism and the polyphonic nature of activist discourse", en New Media and Society, vol: 21, $\mathrm{n}^{\circ} 2$, pp. 507-527. doi: 10.1177/1461444818800242. 
Newman, N. et al. (2019) Reuters Institute Digital News Report 2019. [Consulta: 14 de noviembre de 2019]

Ofori-Parku, S. S. y Moscato, D. (2018) "Hashtag Activism as a Form of Political Action: A Qualitative Analysis of the \#BringBackOurGirls Campaign in Nigerian, UK, and U.S. Press", en International Journal of Communication, vol: 12, pp. 2480-2502.

Page, R. E. (2012). Stories and social media: Identities and interaction. Stories and Social Media: Identities and Interaction. Routledge. https://doi.org/10.4324/9780203148617

Página/12(2019a): "El embarazo infantil "es abuso sexual"', Pagina/12, (1 Febrero). Recuperado de: El embarazo infantil \%22es abuso sexual\%22. [Consulta: 28 de noviembre de 2019]

Página/12 (2019b): "\#NiñasNomadres", Pagina/12, (1 de marzo). Recuperado de https:// www.pagina12.com.ar/177982-ninas-no-madres. [Consulta: 1 de diciembre de 2019]

Papacharissi, Z. (2015): Affective Publics. New York: Oxford University Press.

Papacharissi, Z. y Fatime Oliveira, M. (2012): "Aftective news and networked publics: The rhythms of news storytelling on \#Egypt", en Journal of Communication, vol: $62, n^{\circ} 2$, pp. 266-282.

Peralta, N. (2019): “Cristina Banegas: "Los actores son un espejo y un testimonio que ayuda a pensar"', en Tiempo Argentino, (26 Mayo). Recuperado de: https://www. tiempoar.com.ar/nota/los-actores-son-un-espejo-y-un-testimonio-que-ayuda-apensar. [Consulta: 1 de diciembre de 2019]

Perfil (2018): "MiraComoNosPonemos: la denuncia de Thelma Fardin marcó un boom en las redes sociales", Perfil, (15 Diciembre). Recuperado de: https://www.perfil.com/ noticias/sociedad/miracomonosponemos-la-denuncia-de-thelma-fardin-marco-unboom-en-las-redes-sociales.phtml. [Consulta: 28 de noviembre de 2019]

Piñeiro-Otero, T. y Martínez-Rolán, X. (2016): “Los memes en el activismo feminista en la red. \#viajosola como ejemplo de movilización transnacional", Cuadernos.info, vol: 39, pp. 17-37. doi: 10.7764/cdi.39.1040.

Quevedo-Redondo, R. y Portalés-Oliva, M. (2017): "Imagen y comunicación política en Instagram. Celebrificación de los candidatos a la presidencia del Gobierno", El profesional de la información, vol:26, n 5, pp. 916-927.

Safatle, P. (2019): "Le hicieron una cesárea a la nena de 11 años que fue violada en Tucumán", Infobae, (27 Febrero). Recuperado de: https://www.infobae.com/ sociedad/2019/02/27/le-hicieron-una-cesarea-a-la-nena-de-11-anos-que-fueviolada-en-tucuman/. [Consulta: 28 de noviembre de 2019]

Sampietro,A.ySánchez-Castillo,S.(2020):“Lapromoción delaimagen políticaen Instagram: Un estudio del perfil personal de Santiago Abascal (Vox) en 2018", en Communication \& Society. vol:33, n¹, pp.169-184. Doi: https://doi.org/10.15581/003.33.1.169-184

Softonic (2019): "Fire Shot". Recuperado de: https://fireshot-ie.softonic.com/.

Tambe, A. (2018) "Reckoning with the silences of \#MeToo", Feminist Studies 44, no1. Feminist Studies Inc., pp. 197-202. doi: 10.15767/feministstudies.44.1.0197.

Tarullo, R. (2019a). From saucepans to bandanas, from the streets to the digital space: A perspective on political mobilization in Argentina. In Goldsmiths. Universidad de Londres. Londres.

Tarullo, R. (2019b). Participación y activismo digital: el debate del aborto en las redes. In Periodismo y Sociedad. Facultad de Filología, Traducción y Comunicación. Universidad de Valencia. 
The Guardin (2019): "Thousands of young girls denied abortion after rape in Argentina", The Guardian, (5 Marzo). Recuperado de: https://www.theguardian.com/globaldevelopment $/ 2019 / \mathrm{mar} / 05 /$ thousands-young-girls-denied-abortion-argentina. [Consulta: 28 de noviembre de 2019]

Thompson, J. B. (2005): “La nueva visibilidad”, Papers, vol.78, pp. 11-29. DOI: 10.5565/rev/ papers/v78n0.840

Thrall, A. T. et al. (2008): "Star power: Celebrity advocacy and the evolution of the public sphere", International Journal of Press/Politics, vol:13, $\mathrm{n}^{\circ} 4$, pp. 362-385. doi: 10.1177/1940161208319098.

Tippett, E. C. (2018): "The Legal Implications of the MeToo Movement", Minnesota Law Review, 103.

TN (2018): "El día que Thelma Fardin denunció a Juan Darthés por violación", TN.com. ar, (16 Octubre. Recuperado de: https://tn.com.ar/show/basicas/el-dia-que-thelmafardin-denuncio-juan-darthes-por-violacion_1003063 [Consulta: 28 de noviembre de 2019]

UNICEF (2005): La infancia amenazada. Recuperado de: https://www.unicef.org/spanish/ sowc05/sowc05_sp.pdf [Consulta: 10 de noviembre de 2019]

UNICEF (2017): Embarazo y Maternidad en adolescentes menores de 15 años. Hallazgos y desafíos para las políticas públicas. Recuperado de: https://www.unicef.org/argentina/ publicaciones-y-datos [Consulta: 10 de noviembre de 2019]

Van Dijck, J. (2016): La cultura de la conectividad: Una historia crítica de las redes sociales. Buenos Aires: Siglo XXI.

Vivanco, R. (2019): "Niñas no madres", TN.com.ar, (2 de marzo) Disponible en: https:// tn.com.ar/opinion/ninas-no-madres_944383 [Consulta: 28 de noviembre de 2019]

Yang, G. (2016): "Narrative Agency in Hashtag Activism: The Case of \#BlackLivesMatter", en Media and Communication, vol:4, nº4, pp. 13-17. doi: https://doi.org/10.17645/ mac.v4i4.692.

Yin, R. . (1989): Case study research: Design and methods. Newbury Park: Sage Berkeley Seal Press.

Zappavigna, M. (2016) "Social media photography: construing subjectivity in Instagram images", Visual Communication, vol:15, n³, pp. 271-292. 
54 